\title{
Wide-range optical pH imaging of cementitious materials exposed to
}

\section{chemically corrosive environments}

\author{
Bernhard Müller ${ }^{a * *}$, Cyrill Grengg ${ }^{b}$, Viktor Schallert ${ }^{a}$, Marlene Sakoparnigc ${ }^{c}$ Christoph Staudinger ${ }^{a}$, \\ Johanna Breininger ${ }^{a}$, Florian Mittermayr ${ }^{c}$, Birgit Ungerböck ${ }^{a}$, Sergey M. Borisov ${ }^{a}$, Martin Dietzel ${ }^{b}$, Torsten Mayr ${ }^{a}$
}

${ }^{a}$ Institute of Analytical Chemistry and Food Chemistry, Graz University of Technology, Stremayrgasse 9/II, Graz, Austria
${ }^{b}$ Institute of Applied Geosciences, Graz University of Technology, Rechbauerstraße 12, 8010 Graz, Austria
${ }^{c}$ Institute of Technology and Testing of Building Materials, Graz University of Technology, Inffeldgasse 24, 8010 Graz, Austria

Received: 02 November 2018 / Accepted: 14 November 2018 / Published online: 28 November 2018

(C) The Author(s) 2018. This article is published with open access and licensed under a Creative Commons Attribution 4.0 International License.

- The first author was invited for publication of this letter as a winner of the $1^{\text {st }}$ prize in the Young Researcher Competition organized in the framework of the RILEM 253-MCI Conference (Toulouse, France, 25-26 June 2018).

\begin{abstract}
The $\mathrm{pH}$ of concrete-based material is a key parameter for the assessment of its stability and durability, since a change in pH is usually associated with major types of chemical degradation such as carbonation, leaching and acid attacks. Conventional surface pH measurements with potentiometric flat surface electrodes have low spatial resolution, whereas optical pH visualization with indicator dyes (phenolphthalein) only indicates the areas with higher or lower $\mathrm{pH}$ than the $\mathrm{pKa}$ of the indicator. In this regard, it is key to develop wide-range imaging systems, enabling accurate and spatially resolved determination of $\mathrm{pH}$ variability for an advanced knowledge of degradation mechanisms. This contribution presents the enhancements made for a high-resolution optical $\mathrm{pH}$ imaging system based on fluorescent aza-BODIPY indicator dyes. The measurement range was increased to $6 \mathrm{pH}$ units (pH 6.5 to $\mathrm{pH} 12.5)$ by a combination of two indicator dyes. Moreover, background scattering effects were sufficiently eliminated. With the improved sensor foils steep $\mathrm{pH}$ gradients (up to $3 \mathrm{pH}$ units within $2 \mathrm{~mm}$ ) were successfully recorded in various concrete specimens using a macro lens reaching a resolution of down to 35 $\mu \mathrm{m}$ per pixel.
\end{abstract}

Keywords: optical pH sensors; surface $\mathrm{pH}$; $\mathrm{pH}$-sensitive dyes; concrete carbonation; bio-corrosion

\section{Introduction}

To determine the state of repair and durability of concrete structures, the development of $\mathrm{pH}$ over time and space is a key parameter. Chemical degradation mechanisms, such as carbonation, leaching reactions and acid attack, e.g. triggered by concrete - environmental interactions (e.g. aggressive solutions or gases), are directly associated with decreasing $\mathrm{pH}$ in the internal pore solutions and the external fluids [1-4]. In this perspective, detailed knowledge of $\mathrm{pH}$ distribution and associated $\mathrm{pH}$ gradients is crucial to gain a holistic process understanding of the different corrosion mechanisms and kinetics, to advance towards the development of sustainable concrete-based infrastructure. The $\mathrm{pH}$ of fresh Portland cement-based concrete is usually around 13 [5] and mainly controlled by the content of alkali-metals, portlandite, curing conditions and the addition of supplementary cementitious materials (SCMs) [6,7]. Behnood et al (2015) subcategorized state-of-the-art pH assessments for hardened concrete in destructive methods, such as expression of interstitial concrete pore fluids and leaching methodologies, and nondestructive methods, including embedded sensors like potentiometric electrodes and fiber optic sensors [8]. All these methods lack a sufficiently high spatial resolution to fully capture alteration processes [9-14]. Since concrete is a heterogeneous and porous material with various different components, $\mathrm{pH}$ changes usually proceed non-linear [5]. Thereby, the diffusion rates of aggressive fluids and gases are controlled by mineralogical heterogeneities in the microstructure of the concrete and variations in porosity, directly corresponding to $\mathrm{pH}$ alterations $[15,16]$. Accordingly, proper imaging techniques, which can resolve the spatial distribution of $\mathrm{pH}$, are required for the characterization of these non-linear $\mathrm{pH}$ changes.

So far, mainly absorption-based indicator dyes, like phenolphthalein (PHPHT), are used to tackle this problem.

* Corresponding author: Bernhard Müller, Tel: +43 316873 32518, E-mail: bernhard.mueller@tugraz.at 
This concept relies on the change of absorption properties, leading to a change in color depending on the $\mathrm{pH}$. Therefore, classification in areas with higher or lower $\mathrm{pH}$ compared to the indicators pKa value (pH 9.7 in the case of PHPHT) is possible [17]. Their use is quite common, because $\mathrm{pH}$ indicator dyes are easy to use, cost efficient and provide quick analytical output. However, detailed information on the apparent $\mathrm{pH}$ value is not accessible and these unreferenced systems are prone to errors. Moreover, PHPHT is known for its carcinogenic effects and its widespread use should be avoided [18]. The first imaging technique of $\mathrm{pH}$ distribution on strongly alkaline concrete surfaces was introduced by Liu et al. (2017) based on a porphyrinoid dye (TFPLPt) covering a pH range from 11.0 to 13.5 [19]. Therein, dissolved TFPLPt molecules were coated on fractured mortar samples and images were recorded using a digital single lens camera, a white excitation light source and optical filters. The diagnostic bands were characterized in solution (artificial pore solution + TFPLPT and PHPHT) at various $\mathrm{pH}$ levels via transmittance spectroscopy prior to the measurement. Understanding the potential of optical $\mathrm{pH}$ imaging on cementitious materials, we were able to report on a $\mathrm{pH}$ imaging system based on timedomain dual lifetime referencing (t-DLR) [20] utilizing azaBODIPYs as fluorescent $\mathrm{pH}$ indicator dyes [21]. This methodology used a SensiCam from PCO (https://www.pco.de/) for read-out, a red excitation source and an inert, phosphorescent, reference pigment (Egyptian Blue). It resolved the surface $\mathrm{pH}$ of concrete samples between pH 9.35 to 12.35 with lifetime-based, ratiometric images. These results clearly demonstrated the potential of the t-DLR based imaging methodology to obtain high-resolution spatial $\mathrm{pH}$ distribution information. Nevertheless, challenges such as imperfect background compensation under low $\mathrm{pH}$ conditions or the limited $\mathrm{pH}$ range of three units, remained for further development.

Accordingly, this work presents further advances of this highresolution imaging system. By combining two $\mathrm{pH}$ indicator dyes, an extension of the $\mathrm{pH}$ range from $\mathrm{pH} 6.5$ to 12.5 was attained. Further, an alternative referencing pigment, $\mathrm{Cr}$ $G A B$, was used which also acts as an optical barrier, minimizing background influences. To show the versatility of the methodology, different types of concrete samples, exposed to (i) carbonation), (ii) biogenic acid corrosion and (iii) leaching due to soft water were analyzed. Moreover, close-up images of $\mathrm{pH}$ gradients were taken using a macro lens, thus increasing the resolution up to $35 \mu \mathrm{m}$ per pixel.

\section{Methods}

\subsection{Measurement set-up}

The used set-up has been recently described by Grengg \& Müller et al. [21]. In brief, a sensor foil is soaked in $150 \mathrm{mM}$ $\mathrm{NaCl}$ solution and placed on a planar concrete surface (figure 1). By taking two consecutive pictures with the SensiCam from PCO through a RG9 long pass filter, the $\mathrm{pH}$ value of the surface is determined via t-DLR [20]. For t-DLR the first picture is taken during illumination, where the indicator (fluorescence) and the reference pigment (phosphorescence) contribute to the signal. It is divided by the second one, which is taken right after illumination, where only the reference pigment shows emission, due to is long phosphoresce lifetime (figure A1, supporting info). For the measurements described in this work, adjustments in regards of the excitation source were made. Two high-power LED arrays LR CP7P from OSRAM Opto Semiconductors $\mathrm{GmbH}$, with a mean emission wavelength of $635 \mathrm{~nm}$, were used as an excitation source to improve excitation light homogeneity. They were serially connected and operated at $60 \mathrm{~V}$ constant current. The optimized camera settings used for the measurements can be found in table A1 in the supporting info.

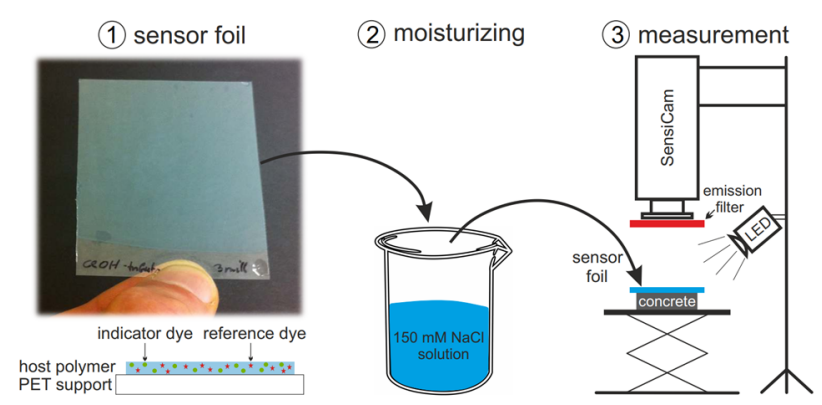

Figure 1. Overview set-up; (1) Sensor foil based on hydrogel D4 comprising the indicator and reference dye; (2) Conditioning in 150 $\mathrm{mM} \mathrm{NaCl}$ solution; (3) Lifetime-based ratiometric imaging of concrete samples with SensiCam and red excitation light [21].

\subsection{Sensor material}

Aza-BODIPYs are a class of $\mathrm{pH}$ indicator dyes, which are well known for their excellent chemical and photochemical stability, their bright near infrared emission and the wide range of available pKa values, which determine the most sensitive point of an optical pH-sensor [22]. A single indicator dye provides thereby an analytically useful range of $3 \mathrm{pH}$-units [23]. Staudinger et al. recently reported on a set of azaBODIPY dyes with similar spectral properties and rather high apparent pKa values, featuring a pure PET effect [24]. Due to the similar absorption spectra a wide-range $\mathrm{pH}$ sensor is realized by mixing two indicators with different apparent $\mathrm{pKa}$ values. Chromium(III)-activated gadolinium borate (Cr-GAB) in the form of microcrystalline powder was used as reference material [25]. This inorganic phosphor exhibits similar spectral properties compared to the used $\mathrm{pH}$ indicator dyes and shows excellent chemical and photochemical stability. Moreover, its phosphorescence displays no cross sensitivity to oxygen, since it's a bulk material. The spectral properties of the used materials are shown in figure 2. As host polymer a polyurethane based hydrogel (HydroMed D4 from Advanced Biomaterials) is used. $100 \mathrm{mg}$ are dissolved in $900 \mathrm{mg}$ of a mixture of ethanol/water $(9+1), 0.08 \%$ wt. of the dye with the lower pKa value ( $\mathrm{m}-\mathrm{OH}$ diCl azaBODIPY, $\mathrm{pKa}=7.53$ ) and $0.12 \%$ wt. of the dye with the higher pKa value $(\mathrm{m}-\mathrm{OH}$ dif azaBODIPY, $\mathrm{pKa}=10.29$ or $\mathrm{m}-\mathrm{OH} \mathrm{Cl}$ azaBODIPY, $\mathrm{pKa}=10.77$ ) are added with respect to the polymer. For referencing, two times the amount of the polymer (200\% wt.) of $\mathrm{Cr}-\mathrm{GAB}$ was added as a fine powder (particle size $\sim 5 \mu \mathrm{m}$ ) and suspended in the polymer solution. The resulting sensor formulation was knife-coated on a $125 \mu \mathrm{m}$ thick PET foil from DuPont Teijin Films (Melinex 506) using a 3 mil $(76 \mu \mathrm{m}$ ) wet film knife from 
Byke. The resulting sensor film has an approximate thickness of $19 \mu \mathrm{m}$ after evaporation of the volatile compounds. Due to a water uptake of $50 \%$ of the hydrogel, the sensor film has an estimated thickness of $25 \mu \mathrm{m}$ in the wet state. The foils were cut into $5 \times 5 \mathrm{~cm}$ squares to fit the samples and stored in 150 $\mathrm{mM} \mathrm{NaCl}$ aqueous solution.

\subsection{Calibration, background evaluation \& measurements}

Calibration was done using solutions of $10 \mathrm{mM}$ of an appropriate buffer substance (acetic acid, MES, phosphate, TRIS, CHES, and CAPS; see table A2 in the supporting info) and $150 \mathrm{mM} \mathrm{NaCl}$. The solutions were adjusted to appropriate $\mathrm{pH}$ with $3 \mathrm{M} \mathrm{NaOH}$ or $\mathrm{HCl}$ using a potentiometric $\mathrm{pH}$ electrode from Mettler Toledo (InLab ${ }^{\circledR}$ Routine Pro). For each calibration point the sensor foil was soaked in buffer, placed under the camera on a black background within the focus of the lens, and pictures were taken. Data processing is done as described by Grengg \& Müller et al. [21]. The mean ratiometric value of each picture is plotted against the appropriate $\mathrm{pH}$ value and the resulting curve is fitted using the Boltzmann equation (equation 1 ) to gain the calibration function:

$$
R=B+\frac{A-B}{1+10^{\frac{(p H-V 50)}{\text { slope }}}}
$$

Where $R$ represents the ratio, $A$ the top value, $B$ the bottom value, $p H$ the $\mathrm{pH}$ value, $V_{50}$ the point of inflection and slope the slope in the point of inflection of the Boltzmann function.

For the evaluation of the influence of the background the sensor foil was again soaked in defined buffer, as described above. However, instead of placing the foil on a black background, it was put on a wet piece of concrete, which was wrapped in cellophane. Pictures were taken and the resulting ratio values converted to $\mathrm{pH}$ values using the according calibration.

Measurements on concert samples were performed by placing the calibrated sensor foil, preconditioned in $150 \mathrm{mM}$ $\mathrm{NaCl}$ solution, on planar samples. Pictures were taken after one minute and the resulting ratio values converted to $\mathrm{pH}$ with the according calibration function.

\subsection{Concrete sample}

For the surface $\mathrm{pH}$ measurements three different concrete types were used which had been exposed to corrosive environments either in lab or in the field. Images of theses concrete specimens were recorded using a Keyence VHX5000 Digital-Microscope.

\section{Sprayed Concrete (SpC)}

The first concrete type was a wet-mix shotcrete that was produced during real scale trials within the ASSpC research project (Advanced and Sustainable Sprayed Concrete research project; FFG project-No. 856080). The cement was a CEMII/B-M(S,L,Q) $52.5 \mathrm{~N}$ and the $\mathrm{w} / \mathrm{c}$ ratio was $0.48 .6 \%$ of an alkali free accelerator and dolomite aggregates from 0-8 $\mathrm{mm}$ were used. The 28 day compressive strength was $\sim 56 \mathrm{MPa}$. At 69 days of age, a $70 \mathrm{~mm}$ drill core was extracted from a larger specimen and stored for 7 days at $65 \%$ r.h. and $20^{\circ} \mathrm{C}$.

Consequently, the drill core was treated in a $\mathrm{CO}_{2}$ climatic chamber at $65 \%$ r.h., $20^{\circ} \mathrm{C}$ and a $\mathrm{CO}_{2}$ concentration of $2 \%$ for 28 days. Thereafter, fresh cross-section areas were produced by cutting the specimens with an angle grinder. In order to prevent further surface $\mathrm{pH}$ alterations, samples were stored in a desiccator under nitrogen atmosphere.

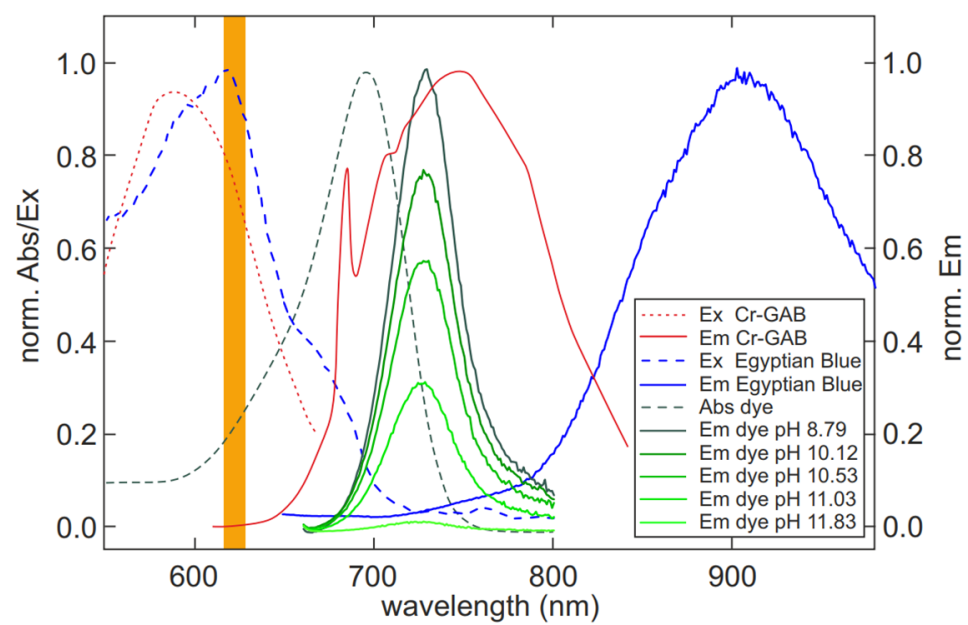

Figure 2. Absorption (Abs), excitation (Ex) and emission (Em) spectra of pH indicator dye (m-OH $\mathrm{Cl}$ azaBODIPY, pKa= 10.77) and reference materials. The emission of $\mathrm{Cr}-\mathrm{GAB}$ matches the fluorescence of the indicator dye better than the emission of previously used Egyptian Blue. The orange bar indicates the wavelengths of the excitation source $(635 \mathrm{~nm})$ used for the imaging system. 


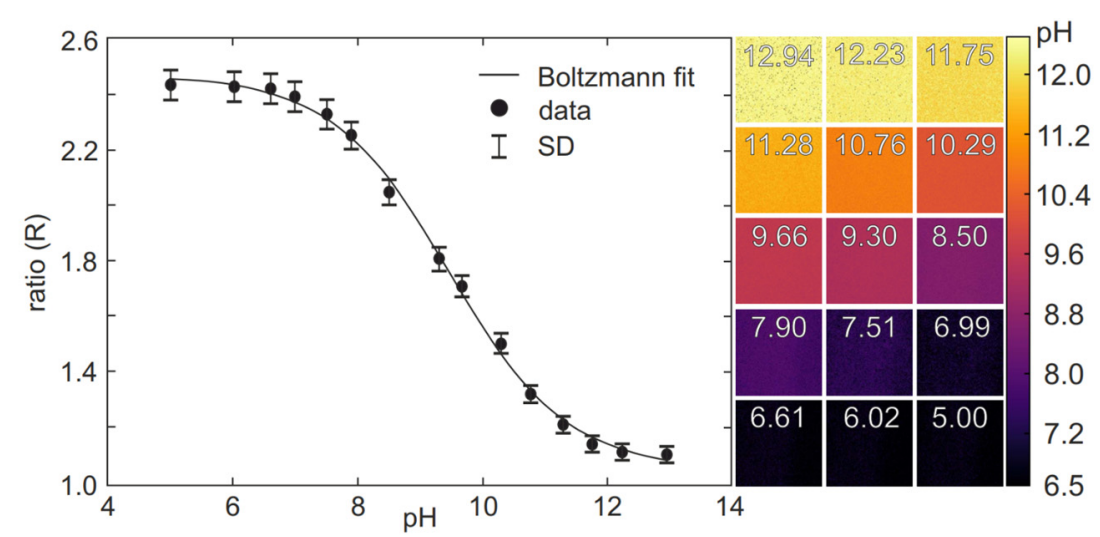

Figure 3. Left: Calibration function of the sensor foil combining the indicators $\mathrm{m}-\mathrm{OH}$ diCl azaBODIPY $(\mathrm{pKa}=7.53)$ and $\mathrm{m}-\mathrm{OH}$ diF azaBODIPY $(\mathrm{pKa}=$ 10.29), which was used for sample measurements. The point of inflection $\left(V_{50}\right)$ is at $\mathrm{pH} 9.47$ with a sensitivity (slope) of $2.16 \mathrm{pH}$ units per $\mathrm{R}$. The top value $(A)$ is 2.47 and the bottom $(B)$ value 1.05. Right: False color images of sensor foil in calibration buffer with according $\mathrm{pH}$ value..

\section{Ultra High-Performance Fiber-Reinforced Concrete (UHPFRC)}

The second concrete type was an Ultra High-Performance Fiber-Reinforced Concrete (UHPFRC) with a water/binder ratio of 0.2 and a compressive strength of $\sim 190 \mathrm{MPa}$. The UHPFRC contained micro-steel fibers and the maximum grain size for the quartz sand used was $<1 \mathrm{~mm}$. From a larger specimen a $4 \times 4 \times 8 \mathrm{~cm}^{3}$ prim was cut before placing it for 12 months in a sewer system, strongly affected by biogenic acid corrosion. A detailed characterization of the exposure system is given elsewhere [26,27]. In brief, prevailing environmental conditions comprised r.h. levels of between 80 and $100 \%$ and high concentrations of hydrogen sulfide $\left(\mathrm{H}_{2} \mathrm{~S}\right)$ (average of 34 ppm; peak levels of $350 \mathrm{ppm}$ ) and $\mathrm{CO}_{2}$ (1000 to $6200 \mathrm{ppm}$ ). After sample collection, concrete specimens were dried at 40 ${ }^{\circ} \mathrm{C}$ for $24 \mathrm{~h}$. Thereafter, the sample was stabilized with a two component epoxy resin and fresh cross-section areas were produced by cutting the specimens with an angle grinder. In order to prevent further surface $\mathrm{pH}$ alterations, samples were stored in a desiccator under nitrogen atmosphere until measurement.

\section{Precast Concrete (PCC)}

The third concrete type was a precast concrete (tubings) that was installed 10 years ago in a headrace tunnel of a hydropower plant. Little information is available about the composition and mechanical parameters except for the aggregates used, which were limestone and dolostone fragments made of calcite and dolomite, respectively. In the headrace tunnel, the concrete showed clear signs of softwater-attack as most of the aggregates have been entirely leached away. The process water had an $\mathrm{EC}<100 \mu \mathrm{S} \mathrm{cm}^{-1}$ with very low $\mathrm{Ca}^{2+}\left(\sim 12 \mathrm{mg} \mathrm{L}^{-1}\right)$ and $\mathrm{Mg}^{2+}\left(\sim 1 \mathrm{mg} \mathrm{L}^{-1}\right)$ concentrations. The extracted $50 \mathrm{~mm}$ drill cores were stabilized using a two-component epoxy resin. Fresh crosssection areas were produced by cutting the specimens with an angle grinder. In order to prevent further surface $\mathrm{pH}$ alterations, samples were stored in a desiccator under nitrogen atmosphere until measurement.

\section{Results \& discussion}

\subsection{Improvement of the imaging method}

In this study, we improved our $\mathrm{pH}$-imaging technique by extending $\mathrm{pH}$ measurement range to up to $6 \mathrm{pH}$ units (6.512.5). During laboratory work two foils have been manufactured. The first foil contains a combination of $\mathrm{m}-\mathrm{OH}$ $\mathrm{diCl}$ azaBODIPY ( $\mathrm{pKa}=7.53$ ) and $\mathrm{m}-\mathrm{OH}$ dif azaBODIPY ( $\mathrm{pKa}=$ 10.29). Accordingly, the gap between the pKa values was 2.79 $\mathrm{pH}$ units. Therefore, a nice overlap between the sensitivity ranges of the dyes is guaranteed, resulting in a good fit using the Boltzmann equation (figure 3). For the multi-dye approach to work predictably, it is important that the absorption spectra of the dyes do not change with the $\mathrm{pH}$ (dyes based solely on photoinduced electron transfer) in order to guarantee constant phosphorescence from the reference dye [24]. However, due to the deactivation of protonated dye molecules by deprotonated dye molecules via a Förster resonance energy transfer (FRET) effect, a $50 \%$ higher ratio of the indicator with higher pKa value was used to guarantee equally strong fluorescence signals of both components and to have a symmetrical calibration function. This foil was finally used for the sample measurements. The close-up images were done with the same foil, resulting in a slightly different calibration function due to the use of a macro lens (figure $A 2$, supporting info).

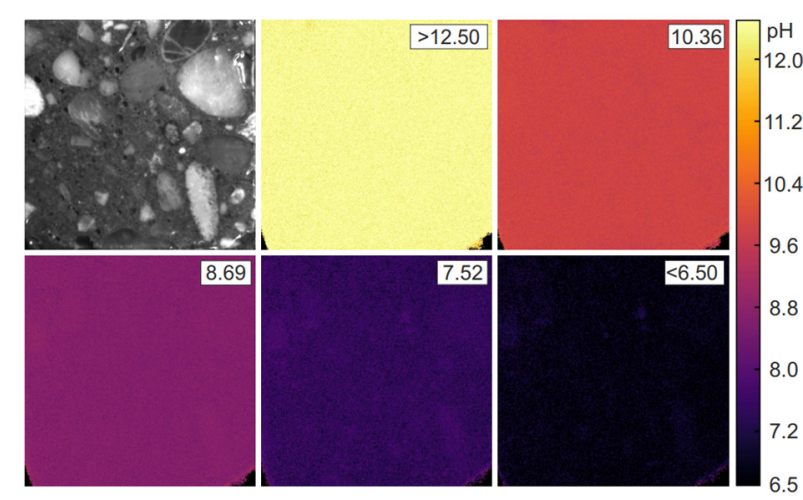

Figure 4. Artefacts at different $\mathrm{pH}$ values due to reflection and scattering from aggregates form the background. Only minor inhomogeneities at low $\mathrm{pH}$ levels are visible. 


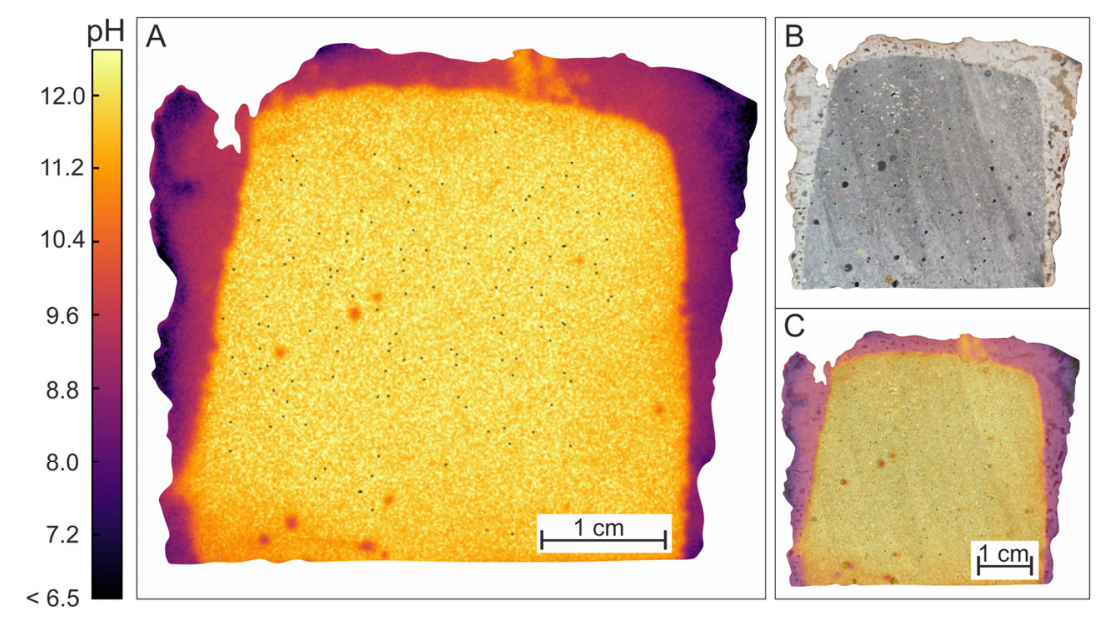

Figure 5. Cross-section of a UHPFRC sample after 12 months of exposure to biogenic acid attack. A) False color pH image of the sample. B) Sample image of the concrete block. C) Overlay of the $\mathrm{pH}$ image and sample image.

The second foil contained a combination of $\mathrm{m}-\mathrm{OH}$ diCl azaBODIPY (pKa= 7.53) and $\mathrm{m}-\mathrm{OH} \mathrm{Cl}$ azaBODIPY (pKa= 10.77), which have a gap between the apparent pKa values of 3.24 $\mathrm{pH}$ units. As previously described, a single $\mathrm{pH}$ dye has a sensitive range of $\pm 1.5 \mathrm{pH}$ units around their pKa value, this results in a gap of about $0.25 \mathrm{pH}$ units, in which this foil has theoretically a lower sensitivity. However, a fit with the Boltzmann equation still provides an acceptable calibration (figure A3, supporting info) although the two separate sigmoidal curves may be adumbrated. The marginally lower quality of the fit outweighs the slightly wider calibration range and no measurements were done with this foil. It was used for the evaluation of the background.

Another improvement of the method is the application of an alternative reference material. $\mathrm{Cr}-\mathrm{GAB}$ was used, since it shows a better spectral overlap with the $\mathrm{pH}$ sensitive dyes (figure 2), compared to the previously used Egyptian Blue [21]. As Cr-GAB inhibits a lower brightness than Egyptian Blue, four times the amount was used. However, this turned out to be beneficial, since the resulting sensor foil was more opaque, ensuring higher robustness from the variation in background scattering and auto-fluorescence. Moreover, due to the better spectral overlap, the emitted light from the indicator and the reference have almost the same wavelength. Therefore referencing barely suffers from reflection and absorption behavior of the background, which is wavelength dependent. The stability of the referencing system is evaluated in figure 4, where the influence of the background at different $\mathrm{pH}$ values is investigated. Barely any artefacts are visible. Only at low $\mathrm{pH}$ values, mild reflections on bright surfaces are visible.

\subsection{Measurements of different concrete samples}

The change in $\mathrm{pH}$ of different types of concrete materials exposed to various chemical attacks has been analyzed using the $\mathrm{pH}$ imaging methodology described. Cross sections of UHPFRC, exposed for 12 months to biogenic acid attack, showed a strong decrease in $\mathrm{pH}$ of more than $6 \mathrm{pH}$ units (figure 5). The intact cementitious matrix in the core region of the sample is still dominated by strongly alkaline $\mathrm{pH}$ conditions above $\mathrm{pH} 12$, while a strong decrease, in two steps, down to a pH below the detectable level of 6.5 is visible at the surface, close to the corrosion layer (see also $\mathrm{pH}$ profile figure A4, supporting info). This drop in $\mathrm{pH}$ is accompanied by complete destruction of the cementitious microstructure, precipitation of sulfate salts and associated loss in textural stability, frequently observed by concretes exposed to biogenic acid attack [28].

On the contrary, the $\mathrm{SpC}$ sample pre-exposed to accelerated carbonation shows a lower $\mathrm{pH}$ gradient, from around $\mathrm{pH} 12$ down to $\mathrm{pH}$ 8.5. This perfectly corresponds to the welldescribed $\mathrm{pH}$ alterations frequently observed during carbonation (figure 6) [15]. A similar pH gradient is observed on the cross-section of the PCC, pre-exposed to soft waters (figure 7).

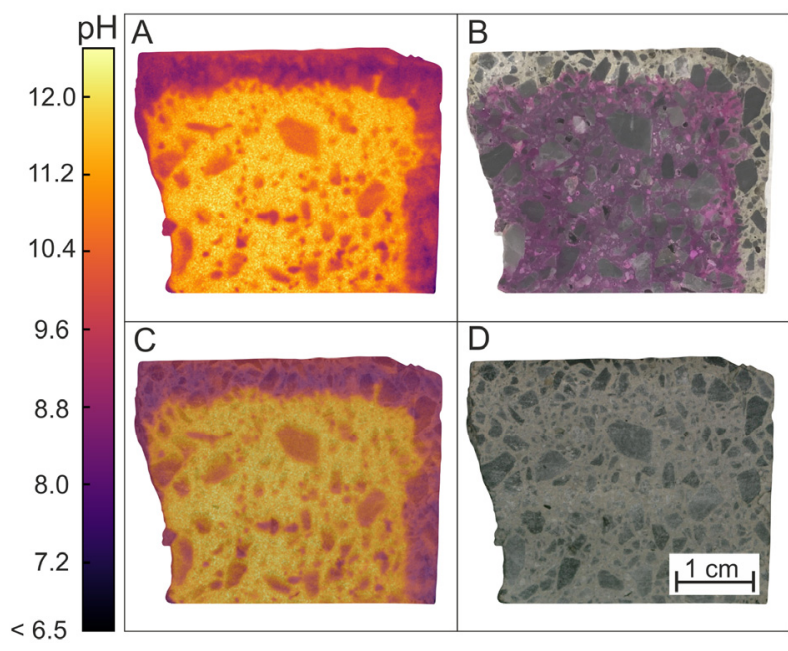

Figure 6. Cross-section of a wet-mix shotcrete with dolomite aggregates treated in a $2 \% \mathrm{CO}_{2}$ atmosphere for 28 days. A) False color $\mathrm{pH}$ image of the sample. B) Microscope image of the same shotcrete sample after short grinding with a $40 \mu \mathrm{m}$ diamond-grinding wheel and spraying with phenolphthalein C) Overlay of the $\mathrm{pH}$ image and sample image. D) Microscope image of the shotcrete specimen.

The successful use of the developed $\mathrm{pH}$ imaging technique on various concrete samples, exhibiting strongly varying chemical and physical properties as well as pre exposure to 
different alteration mechanisms, clearly demonstrates the functionality and robustness of this novel technology.

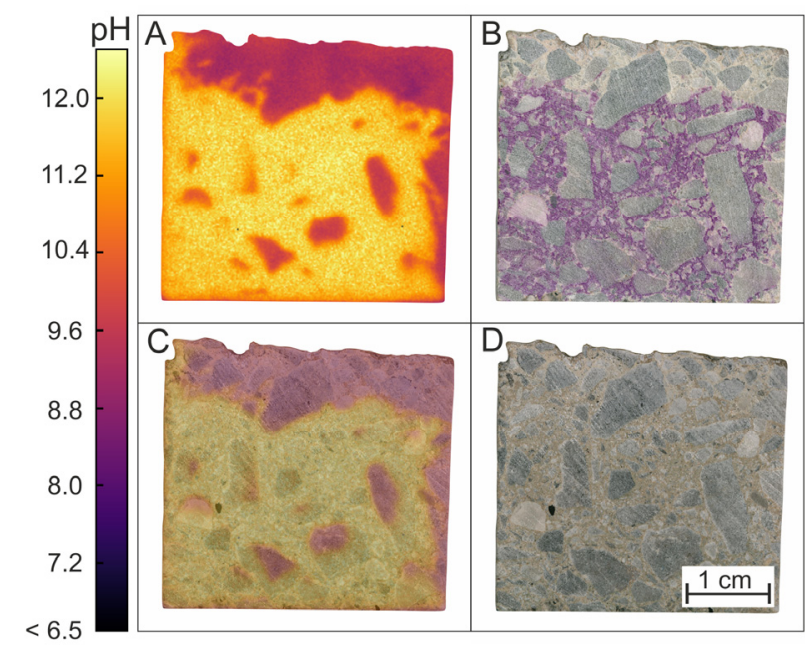

Figure 7. Cross-section of a sample taken from a precast concrete element that was exposed to soft-water for 10 years. The aggregates are dolomite and calcite. A) False color $\mathrm{pH}$ image of the sample. B) Microscope image of the same sample after short grinding with a 40 $\mu \mathrm{m}$ diamond-grinding wheel and spraying with phenolphthalein C) Overlay of $\mathrm{pH}$ image and sample image. D) Microscope image of the specimen.

\subsection{Close-up images \& repeatability}

To gain a better resolution of the observed $\mathrm{pH}$ gradients, close-up $\mathrm{pH}$ images using a macro lens were obtained. The recorded images cover an area of $2.19 \times 1.64 \mathrm{~cm}$ and were taken on the same specimen surfaces as the $\mathrm{pH}$ measurements described above. Thereby, close-up images (figure 8) were processed showing a significantly higher resolution of around $35 \mu \mathrm{m}$ per pixel.

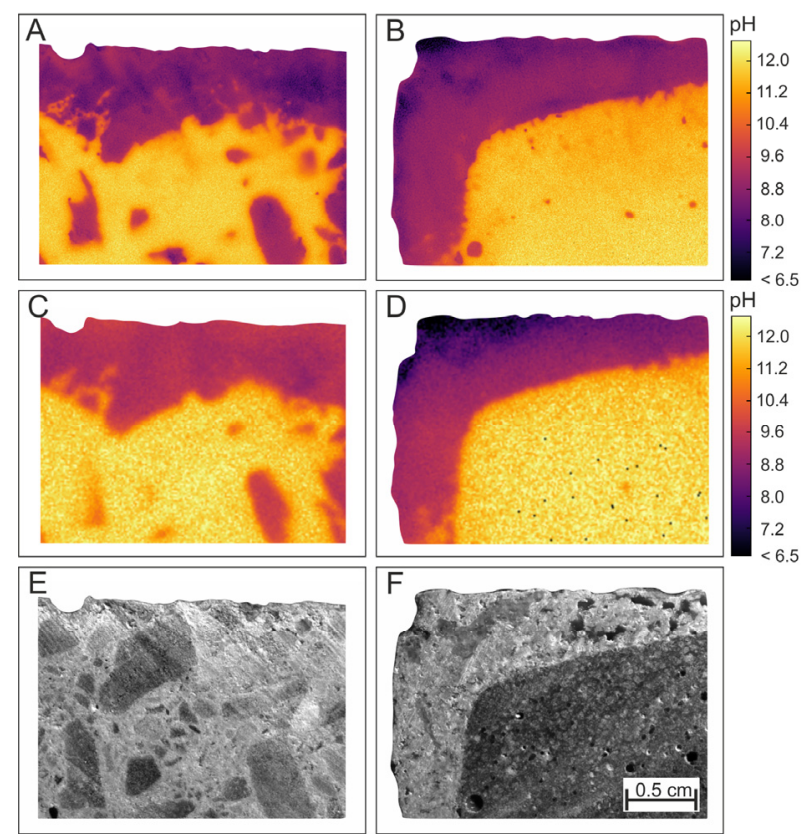

Figure 8. Comparison of close-up false color images (A, B) with the same area of the false color $\mathrm{pH}$ image done with the standard lens (C, $D)$. Picture E \& F show the PCC sample (E) and UHPFRC (F) were the $\mathrm{pH}$ images were recorded.
Additionally, the actual $\mathrm{pH}$ image stayed basically the same, even due to the fact that the measurement was done with two different lenses with two different calibration curves on two different days. This emphasizes the reproducibility of this imaging system.

\section{Conclusion \& outlook}

In this study we improved the usability of t-DLR, based on versatile, $\mathrm{pH}$ sensitive aza-BODIBY dyes, as imaging system for concrete-based materials. An extended $\mathrm{pH}$ range from $\mathrm{pH} 6.5$ to $\mathrm{pH} 12.5$ was achieved by mixing two indicator dyes, enabling the examination of different corrosion scenarios and the surface $\mathrm{pH}$ of three different types of concrete was successfully imaged. For example, it was possible to follow the strong decrease in $\mathrm{pH}$ of more than 6 units on UHPFRC, which was strongly affected by biogenic acid attack corrosion. Thereby a very steep gradient of up to $1.5 \mathrm{pH}$ units per $\mathrm{mm}$ was observed. Close-up images of these zones were taken with a macro lens leading to a resolution of up to $35 \mu \mathrm{m}$ per pixel, which no other technique so far is able to achieve. These close-up images also show the reproducibility of the used imaging method, since they were taken with a different objective and therefore new calibration and still show an almost identical $\mathrm{pH}$ distribution.

For the future, a similar system based on polymer particles would be desirable, since it would open the possibility to measure on rough surfaces. Additionally, the exploration of wavelength-based referencing methods would be interesting, in order to open up the possibility to used standard camera equipment.

Overall, t-DLR based $\mathrm{pH}$ imaging has proven to be a highly promising tool for an advanced understanding of various chemical degradation mechanisms e.g. in the above heterogenic and porous concrete materials. Deciphering the reaction mechanisms and kinetics for alteration features is essentially required to develop tailored sustainable concretebased infrastructure.

\section{Acknowledgement}

Bernhard Freytag, Walter Pichler and the ASSpC team (Advanced and Sustainable Sprayed Concrete research project; FFG project-No. 856080) are acknowledged for providing the concrete samples. We thank Isabel Galan and Joachim Juhart, Helmar Wiltsche and Lukas Troi for fruitful discussions.

\section{References}

[1] M. Stefanoni, U. Angst, B. Elsener, Corrosion rate of carbon steel in carbonated concrete - A critical review. Cem Concr Res (2018) 103: 35-48. https://doi.org/10.1016/i.cemconres.2017.10.007

[2] M. Rosenqvist, A. Bertron, K. Fridh, M. Hassanzadeh, Concrete alteration due to 55years of exposure to river water: Chemical and mineralogical characterisation. Cem Concr Res (2017) 92: 110-120. https://doi.org/10.1016/j.cemconres.2016.11.012

[3] A. Bertron, J. Duchesne, G. Escadeillas, Degradation of cement pastes by organic acids. Mater Struct (2007) 40: 341-354. https://doi.org/10.1617/s11527-006-9110-3 
[4] A. Bertron, M.P. Lavigne, C. Patapy, B. Erable, Biodeterioration of concrete in agricultural, agro-food and biogas plants: state of the art and challenges. RILEM Tech Lett (2017) 2: 83-89. https://doi.org/10.21809/rilemtechlett.2017.42

[5] M. Alexander, A. Bertron, N. De Belie, eds., Performance of CementBased Materials in Aggressive Aqueous Environments, Springer Netherlands, Dordrecht, 2013. https://doi.org/10.1007/978-94-007-5413-3

[6] G. Plusquellec, M.R. Geiker, J. Lindgård, J. Duchesne, B. Fournier, K. De Weerdt, Determination of the $\mathrm{pH}$ and the free alkali metal content in the pore solution of concrete: Review and experimental comparison. Cem Concr Res (2017) 96: 13-26. https://doi.org/10.1016/i.cemconres.2017.03.002

[7] Q. Pu, L. Jiang, J. Xu, H. Chu, Y. Xu, Y. Zhang, Evolution of $\mathrm{pH}$ and chemical composition of pore solution in carbonated concrete. Constr Build Mater (2012) 1: 519-524. https://doi.org/10.1016/j.conbuildmat.2011.09.006

[8] A. Behnood, K. Van Tittelboom, N. De Belie, Methods for measuring pH in concrete: a review. . Constr Build Mater (2016) 105: 176-188. https://doi.org/10.1016/j.conbuildmat.2015.12.032

[9] K. Pásztor, A. Sekiguchi, N. Shimo, N. Kitamura, H. Masuhara, Iridium oxide-based microelectrochemical transistors for $\mathrm{pH}$ sensing. Sens Actuators B: Chemical. (1993) 12: 225-230. https://doi.org/10.1016/0925-4005(93)80023-5

[10] Y.S. Femenias, U. Angst, B. Elsener, PH-monitoring in mortar with thermally-oxidized iridium electrodes, RILEM Tech Lett (2017) 2: 5966. https://doi.org/10.21809/rilemtechlett.2017.37

[11] Y.S. Femenias, U. Angst, B. Elsener, Monitoring $\mathrm{pH}$ in corrosion engineering by means of thermally produced iridium oxide electrodes. Mater Corros (2018) 69: 76-88. https://doi.org/10.1002/maco.201709715

[12] Y.S. Femenias, U. Angst, F. Moro, B. Elsener, Development of a Novel Methodology to Assess the Corrosion Threshold in Concrete Based on Simultaneous Monitoring of $\mathrm{pH}$ and Free Chloride Concentration, Sensors (Basel) (2018) 18. https://doi.org/10.3390/s18093101

[13] A. Safavi, M. Bagheri, Novel optical pH sensor for high and low pH values. Sens Actuators B: Chemical (2003) 90: 143-150. https://doi.org/10.1016/S0925-4005(03)00039-X

[14] O.S. Wolfbeis, Fiber-Optic Chemical Sensors and Biosensors, Anal. Chem. (2004) 76: 3269-3284. https://doi.org/10.1021/ac040049d

[15] J. Stark, B. Wicht, Dauerhaftigkeit von Beton, Springer Berlin Heidelberg, Berlin, Heidelberg, 2013. https://doi.org/10.1007/978-3-642-35278-2

[16] C.L. Page, M.M. Page, eds., Durability of concrete and cement composites, CRC Press, Boca Raton, Fla., 2007.

[17] L.J. Parrott, Cement and Concrete Association, Building Research Establishment, A review of carbonation in reinforced concrete. Cement and Concrete Association, 1987.

[18] J.K. Dunnick', J.R. Hailey, Phenolphthalein Exposure Causes Multiple Carcinogenic Effects in Experimental Model Systems, Cancer Research. 56 (1996) 4922-4926.

[19] E. Liu, M. Ghandehari, C. Brückner, G. Khalil, J. Worlinsky, W. Jin, A Sidelev, M.A. Hyland, Mapping high $\mathrm{pH}$ levels in hydrated calcium silicates. Cem Concr Res (2017) 95: 232-239. https://doi.org/10.1016/j.cemconres.2017.02.001

[20] C. R. Schröder, B. M. Weidgans, I. Klimant, pH Fluorosensors for use in marine systems. Analyst (2005) 130: 907-916. https://doi.org/10.1039/b501306b

[21] C. Grengg, B. Müller, C. Staudinger, F. Mittermayr, J. Breininger, B. Ungerböck, S.M. Borisov, T. Mayr, M. Dietzel, High-resolution optical $\mathrm{pH}$ imaging of concrete exposed to chemically corrosive environments. Cem Concr Res (2018) (accepted). https://doi.org/10.1016/j.cemconres.2018.10.027

[22] M. Strobl, T. Rappitsch, S.M. Borisov, T. Mayr, I. Klimant, NIR-emitting aza-BODIPY dyes - new building blocks for broad-range optical $\mathrm{pH}$ sensors. Analyst (2015) 140: 7150-7153. https://doi.org/10.1039/C5AN01389E

[23] T. Jokic, S.M. Borisov, R. Saf, D.A. Nielsen, M. Kühl, I. Klimant, Highly Photostable Near-Infrared Fluorescent $\mathrm{pH}$ Indicators and Sensors Based on BF2-Chelated Tetraarylazadipyrromethene Dyes. Anal Chem (2012) 84: 6723-6730. https://doi.org/10.1021/ac3011796

[24] C. Staudinger, J. Breininger, I. Klimant, S.M. Borisov, Near-infrared aza-BODIPY dyes with fluorescence response solely due to photoinduced electron transfer: new $\mathrm{pH}$ indicators covering the neutral to highly alkaline range. Analyst (2018) (submitted).

[25] S.M. Borisov, I. Klimant, A versatile approach for ratiometric timeresolved read-out of colorimetric chemosensors using broadband phosphors as secondary emitters, Analytica Chimica Acta (2013) 787: 219-225. https://doi.org/10.1016/j.aca.2013.05.032

[26] C. Grengg, F. Mittermayr, A. Baldermann, M.E. Böttcher, A. Leis, G. Koraimann, P. Grunert, M. Dietzel, Microbiologically induced concrete corrosion: A case study from a combined sewer network, Cem Concr Res (2015) 77: 16-25. https://doi.org/10.1016/j.cemconres.2015.06.011

[27] C. Grengg, F. Mittermayr, G. Koraimann, F. Konrad, M. Szabó, A Demeny, M. Dietzel, The decisive role of acidophilic bacteria in concrete sewer networks: A new model for fast progressing microbial concrete corrosion. Cem Concr Res (2017) 101: 93-101. https://doi.org/10.1016/j.cemconres.2017.08.020

[28] C. Grengg, F. Mittermayr, N. Ukrainczyk, G. Koraimann, S. Kienesberger, M. Dietzel, Advances in concrete materials for sewer systems affected by microbial induced concrete corrosion: A review. Water Res (2018) 134: 341-352.

https://doi.org/10.1016/i.watres.2018.01.043 